\title{
Implementation of physiological functional spinal units in a rigid-body model of the thoracolumbar spine
}

\author{
Wei Wang ${ }^{\mathrm{a}, \mathrm{b}}$, Dongmei Wang ${ }^{\mathrm{a}, *}$, Friedl De Groote ${ }^{\mathrm{b}}$, Lennart Scheys ${ }^{\mathrm{c}}$, Ilse Jonkers ${ }^{\mathrm{b}}$ \\ ${ }^{a}$ School of Mechanical Engineering, Shanghai Jiao Tong University, Shanghai, China \\ ${ }^{\mathrm{b}}$ Department of Movement Sciences, KU Leuven, Leuven, Belgium \\ ${ }^{\mathrm{c}}$ Institute for Orthopaedic Research and Training, KU Leuven, Leuven, Belgium
}

\section{A R T I C L E I N F O}

\section{Article history:}

Accepted 17 October 2019

Available online $\mathrm{xxxx}$

\section{Keywords:}

Rigid-body modelling

Functional spinal unit

Nonlinear stiffness

Spinal kinematics

Follower compressive load

\begin{abstract}
A B S T R A C T
Most of the current rigid-body models of the complete thoracolumbar spine do not properly model the intervertebral joint as the highly nonlinear stiffness is not incorporated comprehensively and the effects of compressive load on stiffness is commonly being neglected. Based on published in vitro data of individual intervertebral joint flexibility, multi-level six degree-of-freedom nonlinear stiffness of functional spinal units was modelled and incorporated in a rigid-body model of the thoracolumbar spine. To estimate physiological in vivo conditions of the entire spine, stiffening effects caused by directly applied compressive loads, and contributions to mono-segmental stiffness from the rib cage as well as multi-segmental interactions in the thoracic spine were analysed and implemented. Forward dynamic simulations were performed to simulate in vitro tests that measured the load-displacement response of the spine under various loading conditions. The predicted kinematic responses of the model were in agreement with in vitro measurements, with correlations between simulated and measured segmental displacements varying between 0.66 and $0.97(\mathrm{p}<0.05)$ and average deviations below $1.6^{\circ}$. Coupling relationships were found between lateral bending and axial rotation. Under compressive loads, the model behaved stiffer and showed a decreased range of motion: The flexion/extension response of the full thoracolumbar spine under compressive loads up to $800 \mathrm{~N}$ was found to strongly correlate with the literature $(r=0.99, p<0.0001)$. The implementation of physiological functional spinal units with nonlinear stiffness properties into rigid-body models can enhance accuracy of biomechanical simulations, and enable detailed analysis of spinal kinematics under complex loading conditions seen in vivo.
\end{abstract}

(ㄷ) 2019 Elsevier Ltd. All rights reserved.

\section{Introduction}

Numerous efforts have been made in developing detailed biomechanical models of the spine based on rigid-body modelling (e.g., Abouhossein et al., 2011; Bruno et al., 2015; Han et al., 2012) or finite element method (e.g., Azari et al., 2018; Ghezelbash et al., 2016). In finite element studies, the complex structures of discs, ligaments and facet joints can be explicitly modelled in detail (Dehghan-Hamani et al., 2019; Khoddam-Khorasani et al., 2018), thereby enabling accurate kinetics analysis in various conditions. Nonetheless, the computational burden is significant (Ghezelbash et al., 2018). In contrast, musculoskeletal simulations using rigidbody models (representing the skeletal system) is another feasible option allowing spine kinematics and kinetics analysis. However,

The model will be available in the online OpenSim repository (simtk.org/ projects/spine-stiffness).

* Corresponding author at: Room 813, Department of Mechanical Engineering, Shanghai Jiao Tong University, Shanghai 200240, China.

E-mail address: dmwang@sjtu.edu.cn (D. Wang). the modelling of the intervertebral joints in the existing rigidbody models needs to be further refined, mainly in terms of the key joint stiffness properties that are currently not (properly) defined (Meng et al., 2015). The stiffness of the functional spinal unit (FSU, i.e., two adjacent vertebrae, the intervertebral joint and all tissues spanning the vertebrae) is known to passively contribute to spinal stability, kinematics, muscle forces and joint reaction forces (Cazzola et al., 2017; Izzo et al., 2013). Numerous in vitro loading-displacement tests (e.g., Heuer et al., 2007) characterized FSU stiffness properties and documented highly nonlinear, level-specific and movement direction-dependent characteristics, that strongly depend on the loading conditions.

State of the art rigid body models of the thoracolumbar spine fail to properly represent the high nonlinearity of FSU stiffness - with stiffness values usually being small for minor FSU displacements (thus inducing small passive forces) but with stiffness typically rapidly increasing with increasing displacement (Izzo et al., 2013) - thereby allowing small active muscle effort near the neutral posture while ensuring stability at the movement 
extremes. In finite element models, nonlinear stiffness is usually incorporated using detailed passive structures or nonlinear deformable beams (Ghezelbash et al., 2018). For rigid-body models, only a few nonlinear stiffness expressions were proposed previously and these were either only for one single FSU (Malakoutian et al., 2016; Weisse et al., 2012), for explicitly modelled ligaments (Liu et al., 2019; Liu et al., 2018) or had not been assessed comprehensively (Cholewicki et al., 1996). Whereas for the lumbar spine, some stiffness formulations are available (with being mainly linear formulations) (Christophy et al., 2012; Meng et al., 2015), for the thoracic spine, the stiffness formulations are even more limited. For instance, all thoracic FSUs in (Ignasiak et al., 2016) share similar linear stiffness properties, thereby ignoring physiologic differences across different spinal levels (Liu et al., 2018). For the thoracic FSU, interactions with the ribcage as well as other thoracic segments need to be taken into account when modelling the nonlinear FSU stiffness. Indeed, the mechanical interaction with the rib cage has a stabilizing and stiffening effect as described by (Liebsch et al., 2017; Mannen et al., 2018). Some studies (Ghezelbash et al., 2016; Ignasiak et al., 2016) approximated the contributions of the ribcage by increasing the thoracic rotational stiffness. Furthermore, some researchers (Dickey and Kerr, 2003; Kettler et al., 2000) found that the in vitro displacements in individual FSUs tend to be larger in mono-segmental test conditions, i.e. only one FSU is tested, compared to multi-segmental condition, where porcine and sheep lumbar specimen were used respectively.

Proper representation of the dependency of the FSU stiffness on compressive load magnitude is barely implemented in rigid-body models of the spine. Indeed, in vitro load-displacement tests (Patwardhan et al., 2003; Stanley et al., 2004) reported increased FSU stiffness with increasing compressive follower loads (CFLs applied by cables that approximate the tangent to the curve of the spine and follows the displacements of vertebral bodies). In finite element simulations, the follower load is typically applied through wrapping cable elements proposed by Shirazi-Adl (2006), or other elements like the two-node thermos-isotropic truss elements as used in (Renner et al., 2007). In rigid-body models, Stokes and Gardner-Morse (2003) previously described the dependence of FSU L2-L3 stiffness on axial compressive preload using an asymptotic exponential equation, where linear stiffness was used. To better simulate in vivo loading conditions using rigid-body models, it is necessary to extrapolate and evaluate the stiffness dependence on compressive load for the full thoracolumbar spine.

Finally, previous stiffness formulations were usually derived based from nominal or averaged experimental measures. Given the large variation among individuals, this approach can be questioned and the added value of accounting for this large variance when modelling the stiffness needs to be evaluated (Abouhossein et al., 2011).

This study therefore presents an advanced rigid-body modelling workflow for the intervertebral joints of the complete thoracolumbar spine that accounts for (1) level-specific six degree-of-freedom (DoF, three rotations and three translations) nonlinear stiffness; (2) the stiffening effect of compressive load; (3) the stabilizing effect of the rib cage and (4) multi-segment interactions in the thoracic spine and (5) potential parameter variance among individuals. Our overall hypothesis is that our extended model of intervertebral joint stiffness accurately represents thoracolumbar spinal mechanical behavior in agreement with published in vitro data.

\section{Methods}

An existing musculoskeletal model of the fully articulated thoracolumbar spine of a non-pathologic male adult (25 years, $175 \mathrm{~cm}, 78 \mathrm{~kg}$ ) (Bruno et al., 2015), developed in the open-source platform OpenSim (version 3.3, Delp et al., 2007), was modified. The original model enabled 3-DoF for each spinal joint, modeled as spherical joints without explicitly modelling of intervertebral disc, ligaments and facet joints. In the current model, all 6-DoF of the intervertebral joints spanning from T1 to S1 were enabled. We used a stepwise procedure as shown in Fig. 1.

We derived an expression describing the passive force caused by FSU stiffness based on experimental data of spinal specimens (see online supplement for the details of steps 1-4):

$$
\begin{aligned}
F_{l}(x, C F L)= & \int_{0}^{x} k_{l}(x, C F L) d x=A_{l}\left(e^{B_{l} \cdot \mu_{r i b} \cdot \mu_{\text {poly }} \cdot x}-1\right) \\
& +r_{C F L l} \cdot c_{2 l}\left(1-e^{c_{1 l} \cdot C F L}\right) \int_{0}^{x} \varepsilon(x) d x
\end{aligned}
$$

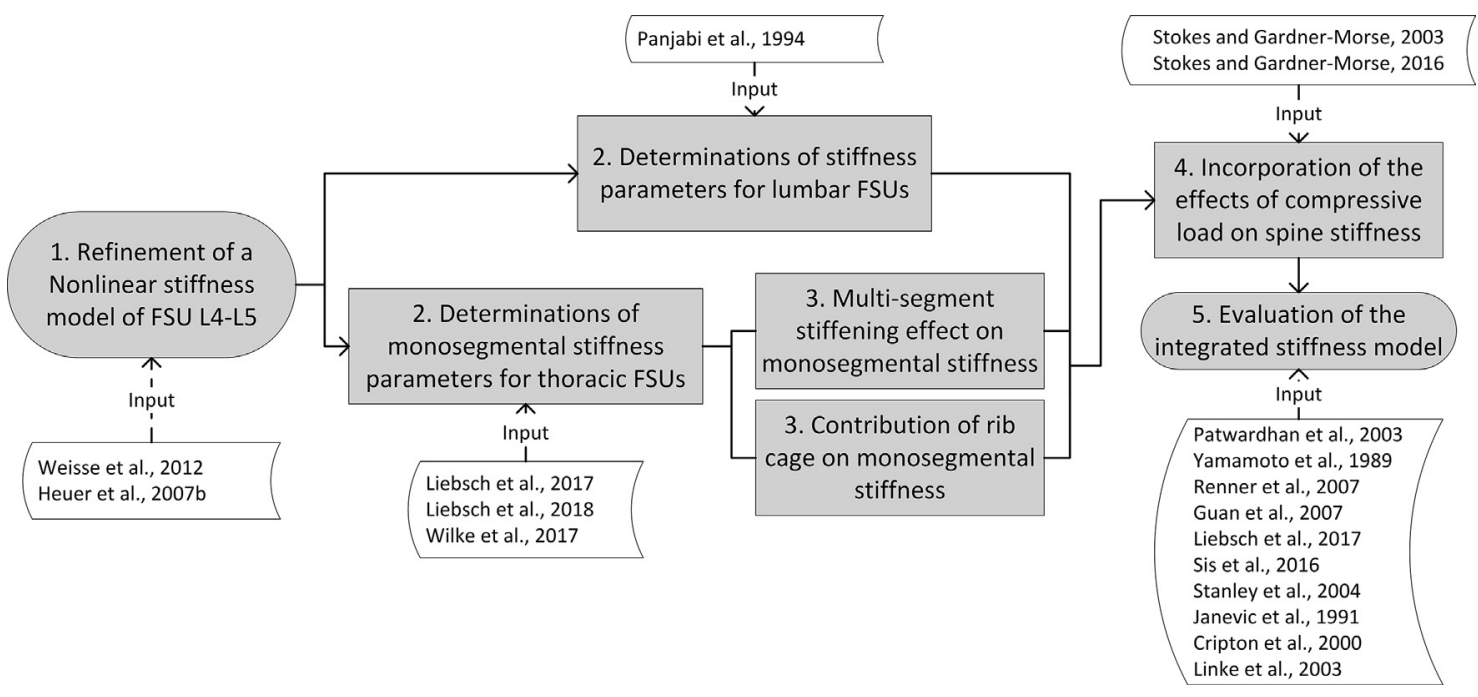

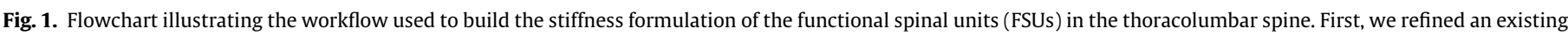

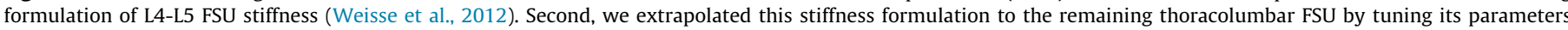

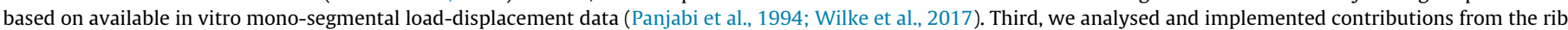

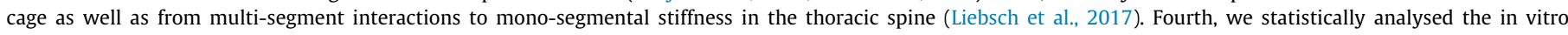

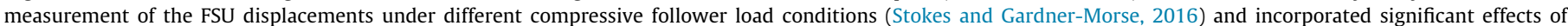

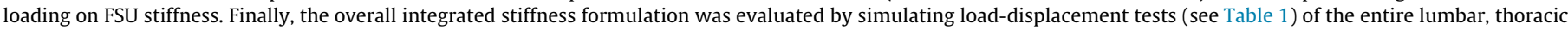
and thoracolumbar spine. 


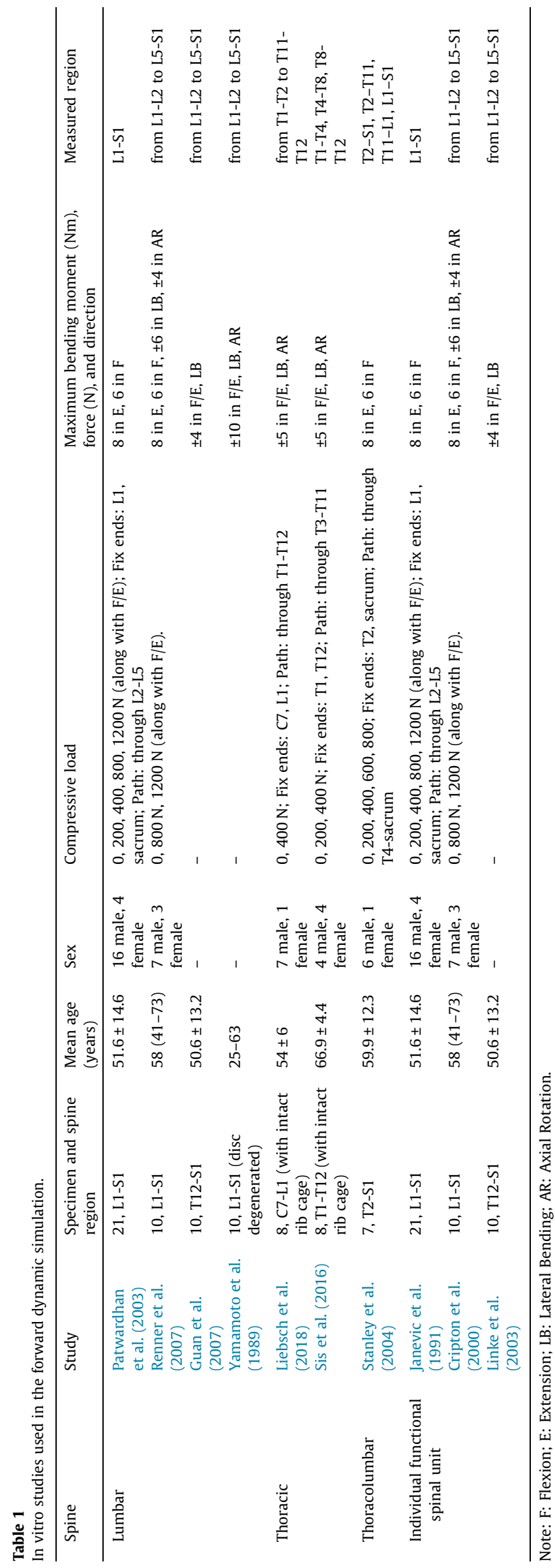

where $F_{l}$ is generalized force (forces and moments along 6-DoFs), $l$ is spinal joint level, $x$ is translational or rotational displacement, $C F L$ is compressive load at level $l$, and $k_{l}$ is stiffness. $A_{l}, B_{l}, c_{1 l}, c_{2 l}$ are coefficients describing nonlinear stiffness and stiffening effect under CFL. $\mu_{\text {poly }}$ and $\mu_{\text {rib }}$ are stiffening factors of multi-segment interaction and rib cage respectively that are only defined for thoracic FSUs. $r_{C F L l}$ is a stiffening scaling factor of CFL effects for different FSUs. Coefficients are determined for flexion (F), extension (E), lateral rotation (LB), axial rotation (AR), anterior-posterior translation, superior-inferior translation, medial-lateral translation. $\varepsilon$ is 1 by default, assuming that stiffness increases evenly with CFL along the entire displacement zone. As an alternative formulation, $\varepsilon(x)$ is a correction factor that accounts for the decrease of the CFL stiffening effect for increasing displacement (see online supplement for details). To account for inter-subject variability, the rotational coefficients $A_{l}$ and $B_{l}$ were determined on the mean value, the mean plus and minus one standard deviation (SD) of the experimental data, resulting in three sets of coefficients representative of nominal, reduced and increased spinal stiffness, hereafter referred to as 'less stiff' and 'stiffer respectively'.

We implemented this integrated FSU stiffness expression (Eq. (1)) in the thoracolumbar spine model using the ExpressionBasedBushingForce element in OpenSim, which generates forces or moments in response to the displacement between two

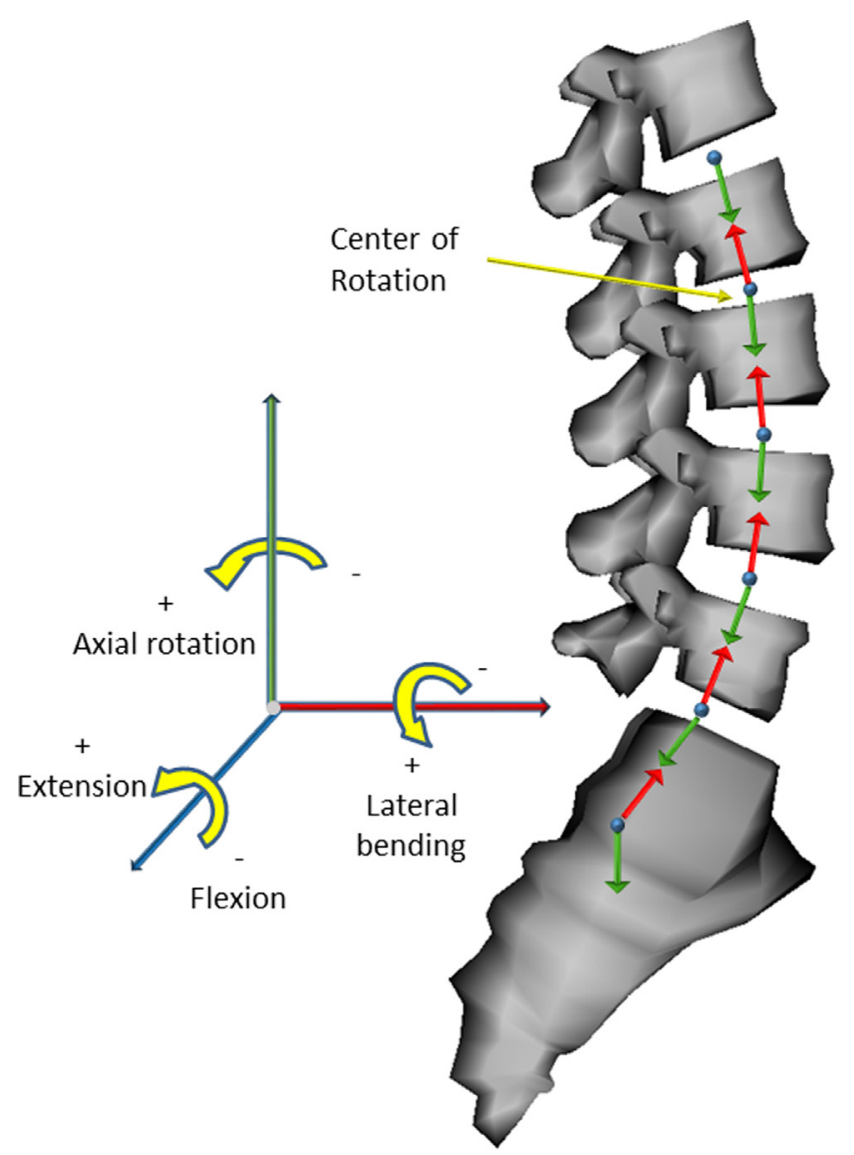

Fig. 2. A schematic showing the path of the compressive follower load. The load vector ideally passes the center of joint rotation of the vertebral body to prevent artefact moments or forces. For instance, for vertebra L2, the cable load passes L2 center of rotation with positive force (arrow in red) aligned with L2 axial rotation axis and negative force (arrow in green) aligned with the L3 axial rotation axis. For the top body that was fixed with the cable, only the negative cable tension was applied in the axial rotation axis of the inferior connected body. (For interpretation of the references to colour in this figure legend, the reader is referred to the web version of this article.) 


\section{Table 2}

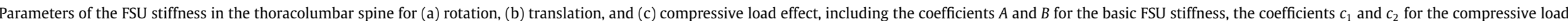

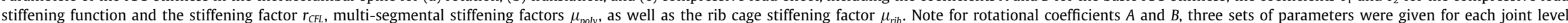
respectively, where the bold values in the first row indicate the norminal parameter and values in the second row indicate the less stiff/stiffer parameters.

\begin{tabular}{|c|c|c|c|c|c|c|c|c|c|c|c|c|c|c|c|c|}
\hline \multirow{2}{*}{$\begin{array}{l}\text { (a) Rotation } \\
\text { Joint Level }\end{array}$} & \multicolumn{4}{|l|}{ Flexion } & \multicolumn{4}{|l|}{ Extension } & \multicolumn{4}{|c|}{ Lateral Bending } & \multicolumn{4}{|c|}{ Axial Rotation } \\
\hline & $\mathrm{A}(\mathrm{Nm})$ & B(deg.-1) & $\mu_{r i b}$ & $r_{C F L}$ & $\mathrm{~A}(\mathrm{Nm})$ & $\mathrm{B}$ (deg.-1) & $\mu_{r i b}$ & $r_{C F L}$ & $\mathrm{~A}(\mathrm{Nm})$ & $\mathrm{B}$ (deg.-1) & $\mu_{r i b}$ & $r_{C F L}$ & $\mathrm{~A}(\mathrm{Nm})$ & $\mathrm{B}$ (deg.-1) & $\mu_{r i b}$ & $r_{C F L}$ \\
\hline T1-T2 & $\begin{array}{l}\mathbf{1 . 5 9} \\
1.26 / 2.35\end{array}$ & $\begin{array}{l}\mathbf{0 . 3 2} \\
0.29 / 0.34\end{array}$ & 1.33 & 1.03 & $\begin{array}{l}\mathbf{0 . 0 4} \\
0.01 / 0.20\end{array}$ & $\begin{array}{l}\mathbf{0 . 5 7} \\
0.54 / 0.60\end{array}$ & 1.33 & 0.04 & $\begin{array}{l}\mathbf{0 . 2 8} \\
0.11 / 0.62\end{array}$ & $\begin{array}{l}\mathbf{0 . 5 0} \\
0.61 / 0.40\end{array}$ & 1.59 & 0.23 & $\begin{array}{l}\mathbf{0 . 4 1} \\
0.29 / 0.63\end{array}$ & $\begin{array}{l}\mathbf{0 . 4 3} \\
0.41 / 0.44\end{array}$ & 2.25 & 0.38 \\
\hline T2-T3 & $\begin{array}{l}\mathbf{3 . 4 5} \\
1.56 / 17.28\end{array}$ & $\begin{array}{l}\mathbf{0 . 3 1} \\
0.30 / 0.23\end{array}$ & 1.76 & 2.15 & $\begin{array}{l}\mathbf{0 . 3 2} \\
0.11 / 1.60\end{array}$ & $\begin{array}{l}\mathbf{0 . 6 5} \\
0.60 / 0.65\end{array}$ & 1.76 & 0.44 & $\begin{array}{l}\mathbf{0 . 8 0} \\
0.73 / 1.91\end{array}$ & $\begin{array}{l}\mathbf{0 . 4 7} \\
0.31 / 0.77\end{array}$ & 1.59 & 0.60 & $\begin{array}{l}\mathbf{0 . 5 6} \\
0.46 / 2.17\end{array}$ & $\begin{array}{l}\mathbf{0 . 8 1} \\
0.54 / 1.11\end{array}$ & 3.03 & 1.43 \\
\hline T3-T4 & $\begin{array}{l}\mathbf{6 . 5 4} \\
4.21 / 20.28\end{array}$ & $\begin{array}{l}\mathbf{0 . 2 2} \\
0.23 / 0.13\end{array}$ & 1.73 & 2.65 & $\begin{array}{l}\mathbf{0 . 2 2} \\
0.07 / 1.10\end{array}$ & $\begin{array}{l}\mathbf{0 . 7 7} \\
0.73 / 0.75\end{array}$ & 1.73 & 0.40 & $\begin{array}{l}\mathbf{1 . 2 9} \\
1.02 / 2.07\end{array}$ & $\begin{array}{l}\mathbf{0 . 3 0} \\
0.25 / 0.35\end{array}$ & 1.70 & 0.48 & $\begin{array}{l}\mathbf{0 . 4 2} \\
0.26 / 0.88\end{array}$ & $\begin{array}{l}\mathbf{0 . 5 0} \\
0.47 / 0.50\end{array}$ & 5.64 & 0.48 \\
\hline T4-T5 & $\begin{array}{l}\mathbf{2 . 2 6} \\
0.99 / 11.30\end{array}$ & $\begin{array}{l}\mathbf{0 . 5 3} \\
0.60 / 0.27\end{array}$ & 4.45 & 3.00 & $\begin{array}{l}\mathbf{0 . 3 1} \\
0.22 / 0.79\end{array}$ & $\begin{array}{l}\mathbf{0 . 7 5} \\
0.56 / 1.05\end{array}$ & 4.45 & 0.54 & $\begin{array}{l}\mathbf{0 . 9 9} \\
0.84 / 1.29\end{array}$ & $\begin{array}{l}\mathbf{0 . 3 9} \\
0.34 / 0.46\end{array}$ & 1.78 & 0.55 & $\begin{array}{l}\mathbf{0 . 8 2} \\
0.46 / 1.86\end{array}$ & $\begin{array}{l}\mathbf{0 . 4 1} \\
0.42 / 0.36\end{array}$ & 3.93 & 0.71 \\
\hline T5-T6 & $\begin{array}{l}\mathbf{6 . 8 4} \\
6.66 / 7.27\end{array}$ & $\begin{array}{l}\mathbf{0 . 2 1} \\
0.16 / 0.32\end{array}$ & 1.93 & 2.62 & $\begin{array}{l}\mathbf{0 . 2 4} \\
0.02 / 1.20\end{array}$ & $\begin{array}{l}\mathbf{0 . 7 3} \\
0.83 / 0.98\end{array}$ & 1.93 & 0.40 & $\begin{array}{l}\mathbf{0 . 4 7} \\
0.35 / 1.94\end{array}$ & $\begin{array}{l}\mathbf{0 . 5 9} \\
0.40 / 0.89\end{array}$ & 1.94 & 0.53 & $\begin{array}{l}\mathbf{0 . 7 6} \\
0.39 / 2.51\end{array}$ & $\begin{array}{l}\mathbf{0 . 3 9} \\
0.38 / 0.32\end{array}$ & 4.68 & 0.61 \\
\hline T6-T7 & $\begin{array}{l}\mathbf{2 . 9 0} \\
1.53 / 10.47\end{array}$ & $\begin{array}{l}\mathbf{0 . 3 8} \\
0.43 / 0.21\end{array}$ & 1.89 & 2.38 & $\begin{array}{l}\mathbf{0 . 2 5} \\
0.01 / 1.25\end{array}$ & $\begin{array}{l}\mathbf{0 . 7 1} \\
0.83 / 1.01\end{array}$ & 1.89 & 0.40 & $\begin{array}{l}\mathbf{0 . 7 2} \\
0.26 / 3.60\end{array}$ & $\begin{array}{l}\mathbf{0 . 4 6} \\
0.45 / 0.38\end{array}$ & 1.80 & 0.52 & $\begin{array}{l}\mathbf{1 . 8 5} \\
1.10 / 5.01\end{array}$ & $\begin{array}{l}\mathbf{0 . 2 3} \\
0.23 / 0.18\end{array}$ & 2.55 & 0.75 \\
\hline T7-T8 & $\begin{array}{l}3.71 \\
2.18 / 10.61\end{array}$ & $\begin{array}{l}\mathbf{0 . 6 2} \\
0.68 / 0.39\end{array}$ & 3.45 & 6.31 & $\begin{array}{l}\mathbf{0 . 9 5} \\
0.49 / 2.69\end{array}$ & $\begin{array}{l}\mathbf{0 . 5 1} \\
0.53 / 0.40\end{array}$ & 3.45 & 0.89 & $\begin{array}{l}\mathbf{0 . 7 2} \\
0.40 / 1.89\end{array}$ & $\begin{array}{l}\mathbf{0 . 5 1} \\
0.50 / 0.45\end{array}$ & 2.03 & 0.62 & $\begin{array}{l}\mathbf{0 . 4 7} \\
0.18 / 1.77\end{array}$ & $\begin{array}{l}\mathbf{0 . 5 6} \\
0.60 / 0.43\end{array}$ & 1.97 & 0.64 \\
\hline T8-T9 & $\begin{array}{l}\mathbf{3 . 4 4} \\
0.51 / 17.20\end{array}$ & $\begin{array}{l}\mathbf{0 . 3 8} \\
0.61 / 0.23\end{array}$ & 0.99 & 2.82 & $\begin{array}{l}\mathbf{0 . 6 8} \\
0.27 / 3.40\end{array}$ & $\begin{array}{l}\mathbf{0 . 6 9} \\
0.70 / 0.48\end{array}$ & 0.99 & 1.03 & $\begin{array}{l}\mathbf{0 . 9 0} \\
0.31 / 3.08\end{array}$ & $\begin{array}{l}\mathbf{0 . 5 6} \\
0.72 / 0.36\end{array}$ & 1.34 & 0.92 & $\begin{array}{l}\mathbf{1 . 2 0} \\
1.13 / 2.20\end{array}$ & $\begin{array}{l}\mathbf{0 . 4 4} \\
0.29 / 0.74\end{array}$ & 1.82 & 1.15 \\
\hline T9-T10 & $\begin{array}{l}\mathbf{2 . 3 3} \\
1.82 / 3.51\end{array}$ & $\begin{array}{l}\mathbf{0 . 5 1} \\
0.48 / 0.51\end{array}$ & 0.89 & 2.92 & $\begin{array}{l}\mathbf{0 . 4 7} \\
0.01 / 2.35\end{array}$ & $\begin{array}{l}\mathbf{0 . 6 0} \\
0.90 / 0.87\end{array}$ & 0.89 & 0.57 & $\begin{array}{l}\mathbf{1 . 0 8} \\
0.56 / 3.17\end{array}$ & $\begin{array}{l}\mathbf{0 . 4 2} \\
0.44 / 0.32\end{array}$ & 1.14 & 0.67 & $\begin{array}{l}\mathbf{0 . 4 1} \\
0.32 / 0.57\end{array}$ & $\begin{array}{l}\mathbf{0 . 5 7} \\
0.54 / 0.60\end{array}$ & 1.26 & 0.58 \\
\hline T10-T11 & $\begin{array}{l}3.37 \\
1.58 / 16.85\end{array}$ & $\begin{array}{l}\mathbf{0 . 3 7} \\
0.42 / 0.17\end{array}$ & 1.83 & 2.67 & $\begin{array}{l}\mathbf{0 . 9 3} \\
0.58 / 2.52\end{array}$ & $\begin{array}{l}\mathbf{0 . 6 8} \\
0.58 / 0.70\end{array}$ & 1.83 & 1.38 & $\begin{array}{l}\mathbf{1 . 6 6} \\
0.46 / 8.30\end{array}$ & $\begin{array}{l}\mathbf{0 . 4 0} \\
0.54 / 0.20\end{array}$ & 0.47 & 0.96 & $\begin{array}{l}\mathbf{0 . 8 0} \\
0.55 / 3.77\end{array}$ & $\begin{array}{l}\mathbf{0 . 6 2} \\
0.44 / 0.77\end{array}$ & 1.19 & 1.29 \\
\hline T11-T12(T12-L1) & $\begin{array}{l}\mathbf{3 . 0 1} \\
1.66 / 15.05\end{array}$ & $\begin{array}{l}\mathbf{0 . 3 8} \\
0.39 / 0.18\end{array}$ & - & 2.47 & $\begin{array}{l}\mathbf{0 . 4 4} \\
0.02 / 2.20\end{array}$ & $\begin{array}{l}\mathbf{0 . 6 6} \\
0.98 / 0.69\end{array}$ & - & 0.62 & $\begin{array}{l}\mathbf{1 . 1 3} \\
0.56 / 3.63\end{array}$ & $\begin{array}{l}\mathbf{0 . 5 1} \\
0.55 / 0.36\end{array}$ & - & 0.98 & $\begin{array}{l}\mathbf{2 . 1 7} \\
1.52 / 10.85\end{array}$ & $\begin{array}{l}\mathbf{0 . 4 6} \\
0.34 / 0.41\end{array}$ & - & 2.21 \\
\hline L1-L2 & $\begin{array}{l}\mathbf{1 . 1 2} \\
0.42 / 4.78\end{array}$ & $\begin{array}{l}\mathbf{0 . 6 4} \\
0.74 / 0.39\end{array}$ & - & 1.99 & $\begin{array}{l}\mathbf{3 . 6 1} \\
3.12 / 4.68\end{array}$ & $\begin{array}{l}\mathbf{0 . 2 3} \\
0.18 / 0.32\end{array}$ & - & 1.16 & $\begin{array}{l}\mathbf{5 . 3 0} \\
1.94 / 17.55\end{array}$ & $\begin{array}{l}\mathbf{0 . 1 7} \\
0.24 / 0.10\end{array}$ & - & 0.95 & $\begin{array}{l}\mathbf{4 . 0 7} \\
2.02 / 20.36\end{array}$ & $\begin{array}{l}\mathbf{0 . 3 7} \\
0.27 / 0.67\end{array}$ & - & 3.02 \\
\hline L2-L3 & $\begin{array}{l}\mathbf{0 . 6 2} \\
0.53 / 0.77\end{array}$ & $\begin{array}{l}\mathbf{0 . 5 4} \\
0.49 / 0.61\end{array}$ & & 0.85 & $\begin{array}{l}\mathbf{1 1 . 4 0} \\
11.20 / 11.85\end{array}$ & $\begin{array}{l}\mathbf{0 . 1 3} \\
0.10 / 0.20\end{array}$ & & 1.93 & $\begin{array}{l}\mathbf{3 . 7 2} \\
2.34 / 8.95\end{array}$ & $\begin{array}{l}\mathbf{0 . 1 8} \\
0.19 / 0.13\end{array}$ & & 0.69 & $\begin{array}{l}\mathbf{5 . 9 9} \\
0.70 / 29.93\end{array}$ & $\begin{array}{l}\mathbf{0 . 3 0} \\
0.60 / 0.17\end{array}$ & & 3.44 \\
\hline L3-L4 & $\begin{array}{l}\mathbf{1 . 2 1} \\
0.37 / 6.06\end{array}$ & $\begin{array}{l}\mathbf{0 . 4 1} \\
0.49 / 0.24\end{array}$ & & 1.09 & $\begin{array}{l}\mathbf{1 0 . 2 4} \\
4.11 / 51.20\end{array}$ & $\begin{array}{l}\mathbf{0 . 1 9} \\
0.24 / 0.10\end{array}$ & & 2.65 & $\begin{array}{l}4.11 \\
0.99 / 20.53\end{array}$ & $\begin{array}{l}\mathbf{0 . 1 9} \\
0.28 / 0.10\end{array}$ & & 0.84 & $\begin{array}{l}\mathbf{2 . 1 6} \\
0.67 / 10.82\end{array}$ & $\begin{array}{l}\mathbf{0 . 5 9} \\
0.62 / 0.58\end{array}$ & & 3.25 \\
\hline L4-L5 & $\begin{array}{l}\mathbf{1 . 0 8} \\
1.15 / 0.95\end{array}$ & $\begin{array}{l}\mathbf{0 . 3 4} \\
0.25 / 0.52\end{array}$ & & 0.76 & $\begin{array}{l}\mathbf{4 . 1 6} \\
1.76 / 7.99\end{array}$ & $\begin{array}{l}\mathbf{0 . 2 5} \\
0.26 / 0.29\end{array}$ & & 1.48 & $\begin{array}{l}\mathbf{4 . 5 2} \\
3.99 / 8.37\end{array}$ & $\begin{array}{l}\mathbf{0 . 1 9} \\
0.13 / 0.31\end{array}$ & & 0.90 & $\begin{array}{l}4.15 \\
0.70 / 20.75\end{array}$ & $\begin{array}{l}\mathbf{0 . 4 9} \\
0.57 / 0.79\end{array}$ & & 4.65 \\
\hline L5-S1 & $\begin{array}{l}\mathbf{0 . 6 8} \\
0.47 / 1.13\end{array}$ & $\begin{array}{l}\mathbf{0 . 4 2} \\
0.38 / 0.45\end{array}$ & & 0.63 & $\begin{array}{l}4.75 \\
2.47 / 21.53\end{array}$ & $\begin{array}{l}\mathbf{0 . 1 4} \\
0.15 / 0.08\end{array}$ & & 0.86 & $\begin{array}{l}\mathbf{3 . 7 5} \\
1.81 / 18.73\end{array}$ & $\begin{array}{l}\mathbf{0 . 2 3} \\
0.23 / 0.15\end{array}$ & & 0.98 & $\begin{array}{l}\mathbf{5 . 0 8} \\
0.75 / 25.38\end{array}$ & $\begin{array}{l}\mathbf{0 . 4 9} \\
0.64 / 0.79\end{array}$ & & 5.66 \\
\hline$\mu_{\text {poly }}$ for thoracic spine & 2.46 & & & & & & & & 2.43 & & & & 1.36 & & & \\
\hline (b) Translation & & Anterior & & & & & & & Superior & & & Inferior & & & Medial & ateral \\
\hline $\begin{array}{l}\mathrm{A}(\mathrm{N}) \\
\mathrm{B}\left(\mathrm{mm}^{-1}\right) \\
r_{C F L}\end{array}$ & & $\begin{array}{l}726 \\
0.45 \\
8.17\end{array}$ & & & $\begin{array}{l}14 . \\
0.6 \\
3.3\end{array}$ & & & & $\begin{array}{l}415 \\
0.993 \\
2.58\end{array}$ & & & $\begin{array}{l}221 \\
1.81 \\
0.88\end{array}$ & & & $\begin{array}{l}222 \\
0.738 \\
3.54\end{array}$ & \\
\hline
\end{tabular}

\begin{tabular}{|c|c|c|c|c|c|c|c|c|c|}
\hline (c) Compressive load effect & Flexion & Extension & Lateral Bending & Axial Rotation & Anterior Translation & Posterior Translation & Superior & Inferior & Medial-lateral \\
\hline c1 $(1 / \mathrm{kN})$ & -0.91 & -0.68 & -2.43 & -3.50 & -1.20 & -2.50 & -4.60 & -0.10 & -2.90 \\
\hline c2 $(\mathrm{Nm} / \mathrm{deg}$ or $\mathrm{N} / \mathrm{mm})$ & 2.87 & 2.75 & 6.39 & 1.78 & 152.96 & 163.96 & 345.05 & 2359.25 & 145.28 \\
\hline
\end{tabular}


bushing frames. We modified the OpenSim library of the ExpressionBasedBushingForce element to enable the implementation of CFL stiffening effect. Bushing frames had the same orientation as the body segments and were initially connected at the FSU rotation center. In the anatomic (neutral) position, each pair of bushing frames coincided. We added damping of $1 \mathrm{Ns} / \mathrm{mm}$ for translation and $2.3 \mathrm{Nm} \cdot \mathrm{s} / \mathrm{rad}$ for rotation (Abouhossein et al., 2011). Note that the damping coefficients influenced the convergence speed of our simulations but did not affect the final static poses and hence did not influence our results.

We evaluated the stiffness formulation using published in vitro data (Table 1) of the load-displacement response of lumbar, thoracic and full thoracolumbar spine as well as individual lumbar FSUs under pure moments in F/E, LB and AR (Fig. 1 - step 5). We used OpenSim's Forward Simulation tool to simulate movements of the spine and its FSUs under the experimental loading conditions. Note experimental data used here is different from the experimental data used to define the expressions for stiffness. Such cross-validation is important to avoid overfitting of the experimental data. To further assess the effects of nonlinear stiffness expressions, we included the comparison of the kinematic responses with those of two different linear stiffness expressions used in recently published rigid-body models by (Ignasiak et al., 2016; Senteler et al., 2016).

To simulate the in vitro conditions of isolated ligamentous spine, we modified the model to only keep the thoracolumbar vertebrae, pelvis and sacrum, while removing the other bones and muscles. In addition, we modified the inertial parameters to reflect vertebrae inertia instead of whole trunk inertia: the vertebral mass was set $0.1 \mathrm{~kg}$ for lumbar vertebrae and $0.05 \mathrm{~kg}$ for thoracic vertebrae, and the center of mass (CoM) was set at the midpoint between the superior and inferior joint rotation centers of the vertebral body (associated sensitivity analyses are detailed in supplementary material). To simulate in vitro experiments with intact rib cage, we tripled the mass of the thoracic vertebra $(0.15 \mathrm{~kg})$ and used the CoM position of the original model, i.e., the CoM position was kept anterior to the vertebrae representing the partitioned trunk slice.

CFL was applied by simulating the cable tension in in vitro tests (Patwardhan et al., 2003) (Fig. 2). We refer to vertebrae to which the cable was attached as 'connected bodies', and the load vector ideally passes the center of rotation of the connected body with a pair of equal but opposite loads along the local AR-axes of any two adjacent connected bodies.

All simulations started from the initial unloaded upright standing posture (all FSU displacements zero). Spine movement under the prescribed external load (constant and continuous-time bending moments with or without CFL) was simulated until the model reached static equilibrium, defined as the position where the spine posture stabilized and no further joint displacements occurred. We evaluated the range of motion (RoM) as the range in joint displacement in the final static position between each pair of simulations with opposite bending moments (see Table 1).

Goodness of the proposed FSU stiffness formulation was evaluated based on the correlation between experimental and simulated RoM using Pearson's correlation tests. Correlations were deemed significant for $\mathrm{p} \leq 0.05$. We evaluated the slopes and intercepts of the linear relations. The intercept defines the offset of our sim-

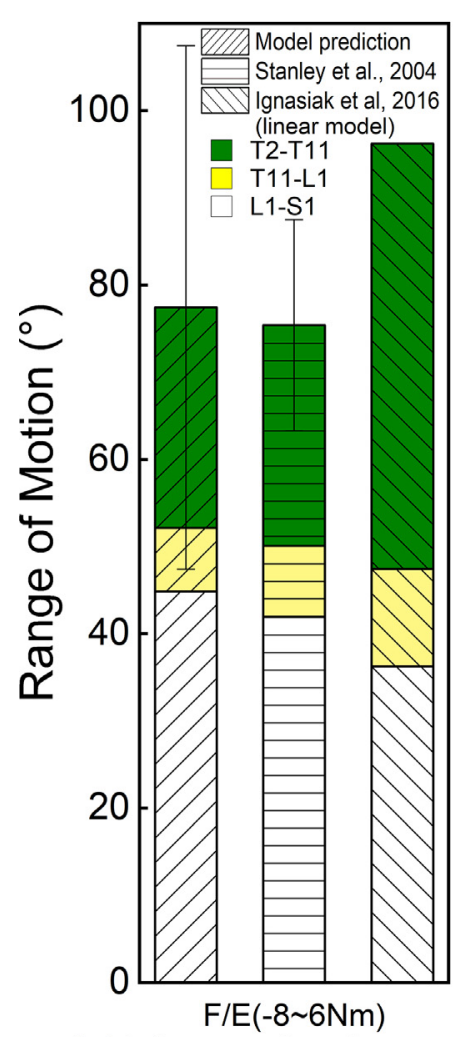

(a) Thoracolumbar spine

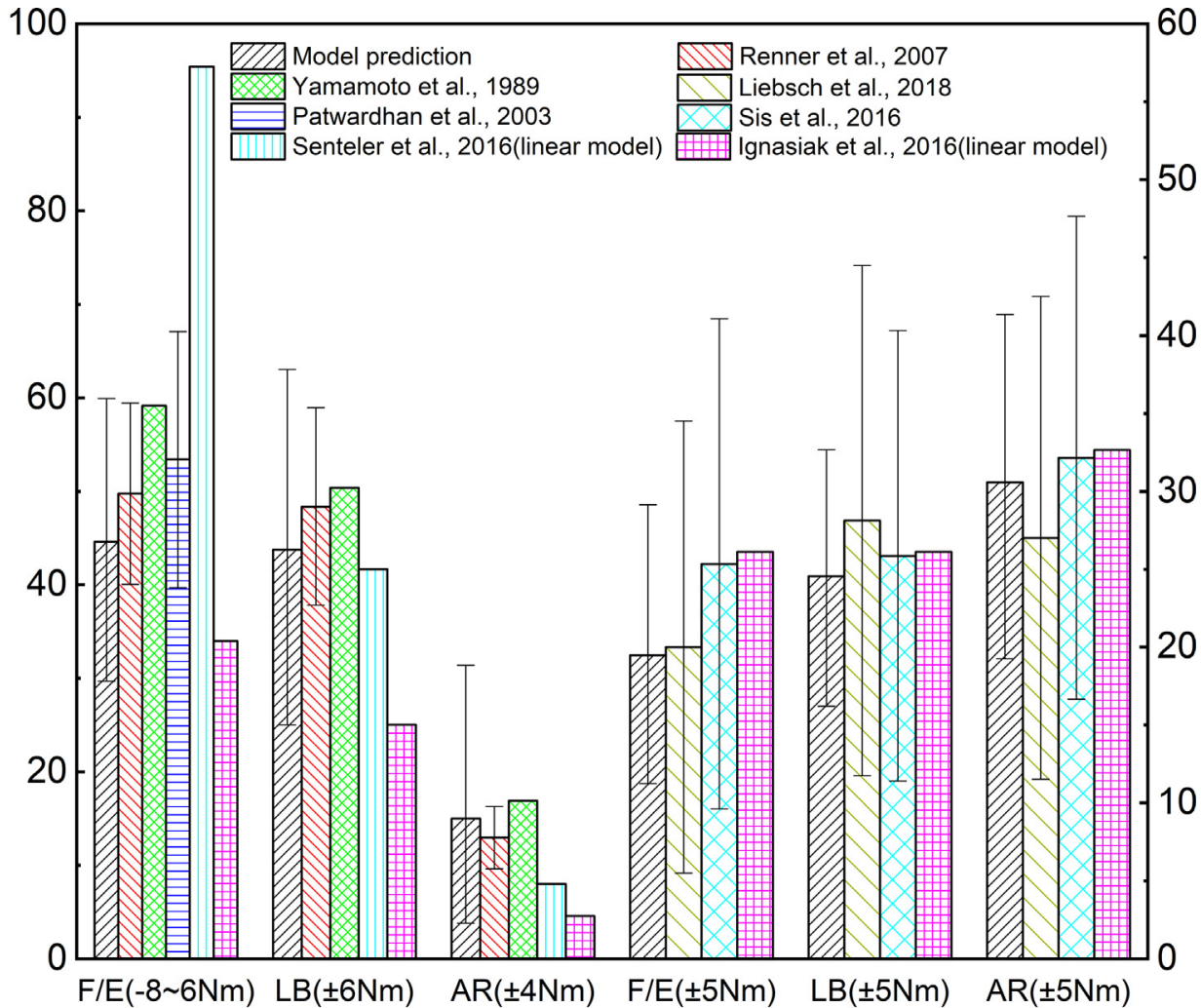

(b) lumbar (left) and thoracic (right) spine

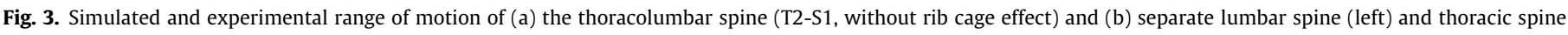

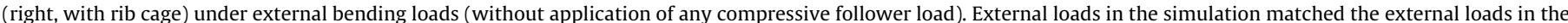

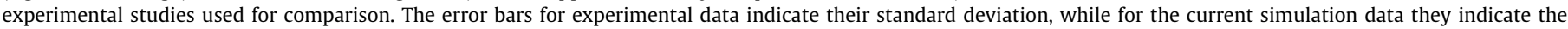
range of the simulation results when using the corresponding 'stiffer' and 'less stiff' stiffness parameters listed in Table 2. 
ulations with respect to the experimental data. Slopes below and above 1 respectively indicate an under- or overestimation of the RoM.

\section{Results}

Model parameters are listed in Table 2, including (1) the coefficients $A$ and $B$ for the basic FSU stiffness (nominal, less stiffer and stiffer), (2) the coefficients $c_{1}$ and $c_{2}$ for the compressive load stiffening function, (3) the stiffening factor $r_{C F L}$, (4) multi-segmental stiffening factors $\mu_{\text {poly }}$, and (5) the rib cage stiffening factor $\mu_{\text {rib. }}$. Experimental data used for building the model was fitted with Rsquared values greater than 0.97 .

\subsection{Kinematic response to bending loads}

As shown in Fig. 3, the simulated total RoM of the full thoracolumbar spine (without rib cage), the separate lumbar and thoracic spine (with rib cage) under different loading conditions (no $\mathrm{CFL}$ ) were all in good agreement with corresponding experiments and within one SD of in vitro data. Also, the range of the simulated range of displacement (shown as the error bars in Fig. 3) from the 'stiffer' and 'less stiff parameter sets successfully captured the reported variance of the in vitro study. The predicted RoM variance was within one SD of the experimental data for all thoracic rota-
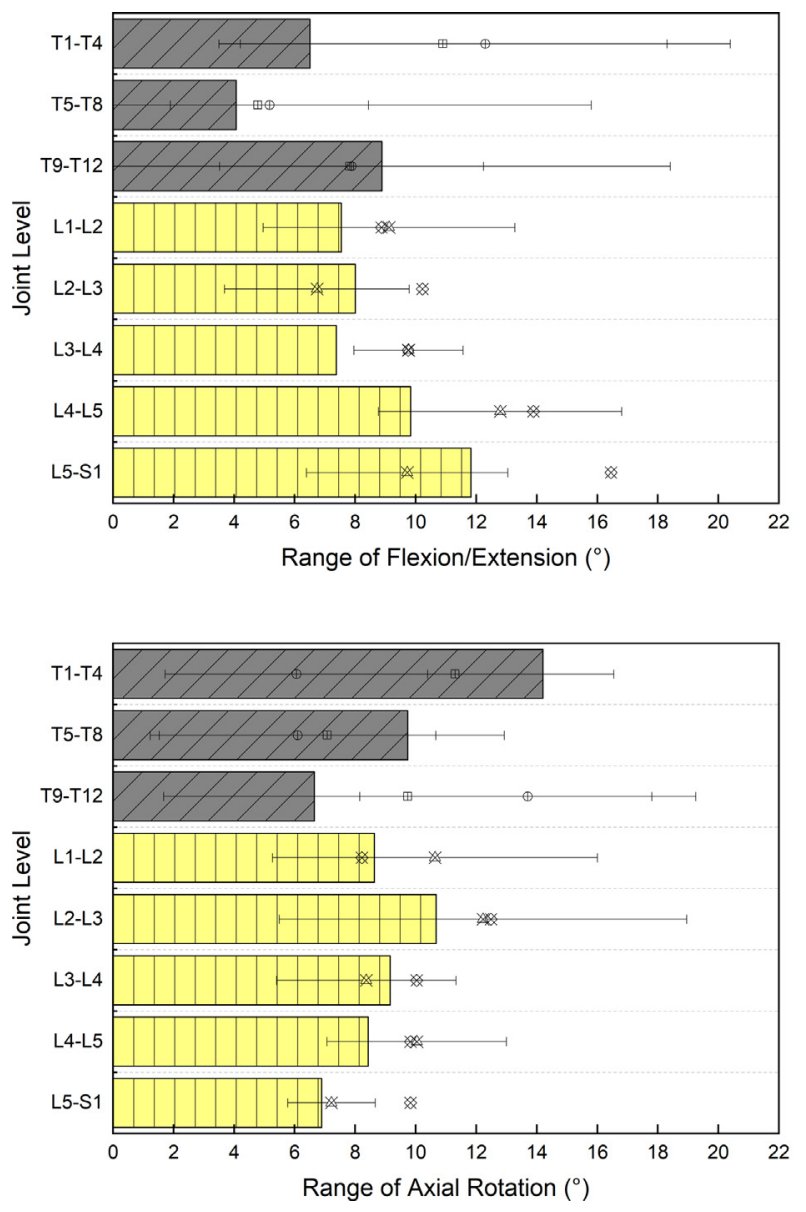

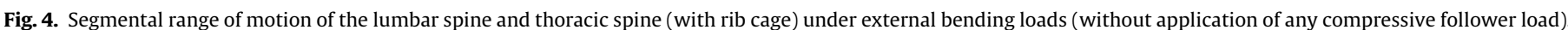

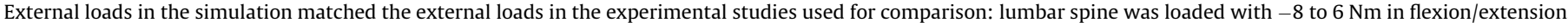

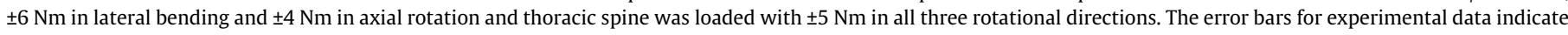

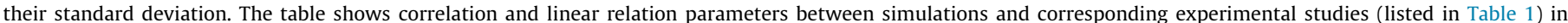

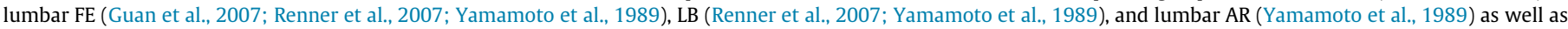
thoracic FE, LB, and AR (Liebsch et al., 2018; Sis et al., 2016). 


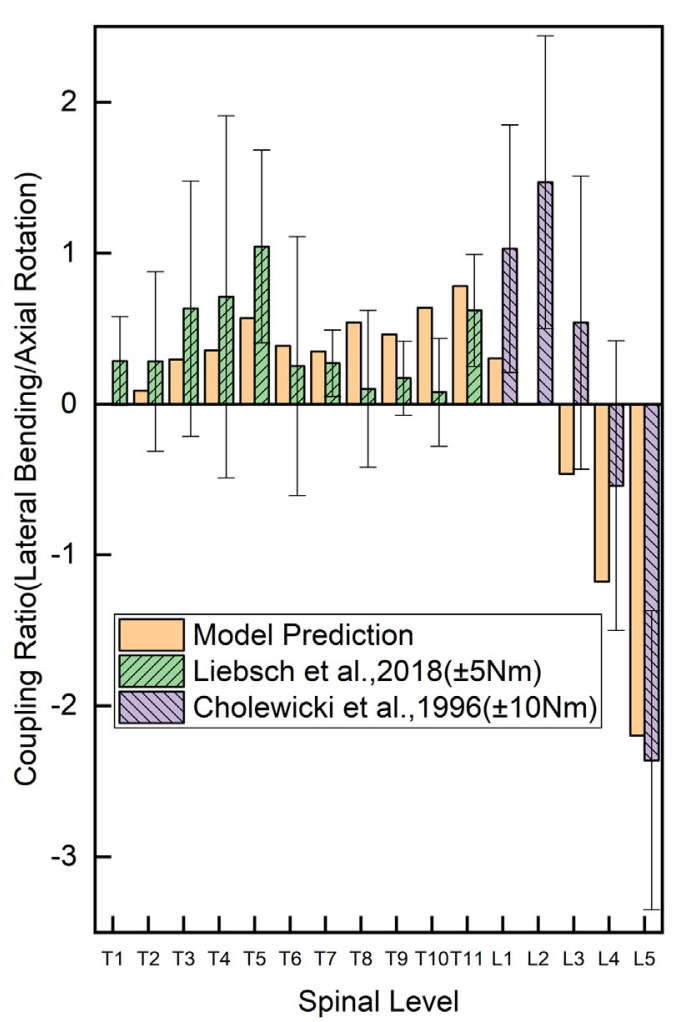

(a)

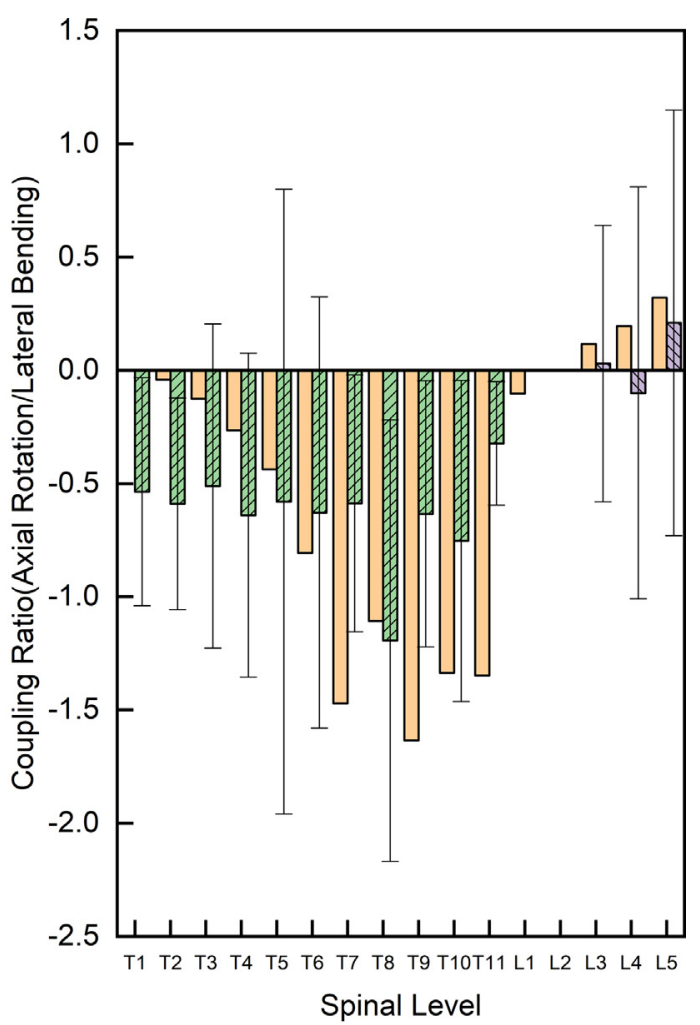

(b)

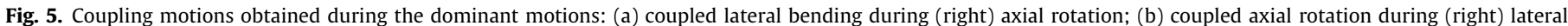

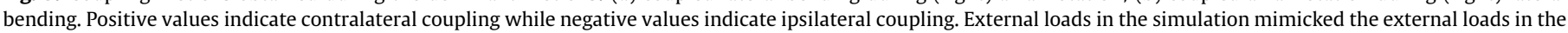

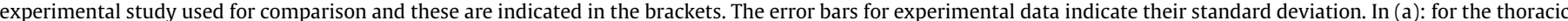

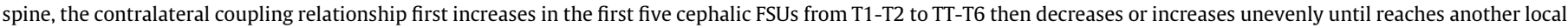

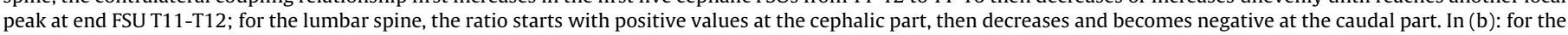

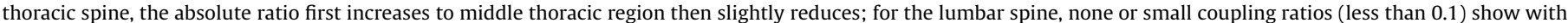
exception for FSU L4-L5 and L5-S1.

changes under large CFL. For example, the entire lumbar spine exhibited a maximum rotation less than $1^{\circ}$ under $C F L=1200 \mathrm{~N}$ (same as (Patwardhan et al., 2003)) and less than $3^{\circ}$ under $\mathrm{CFL}=5000 \mathrm{~N}$. The model successfully captured the decreased flexibility in response to increased CFL for individual FSUs (Fig. 6), separate entire lumbar spine, thoracic spine and full thoracolumbar spine (Fig. 7).

For individual FSU rotations (Fig. 6 (a)-(c)), the normalized rotation to zero CFL closely matched the corresponding experimental data $(\max C F L=2200 \mathrm{~N})$ : the average absolute difference was $3.4 \%$ for $\mathrm{F} / \mathrm{E}, 3.8 \%$ for $\mathrm{LB}, 9.4 \%$ for AR. For individual FSU translations (Fig. 6(d)), both the predicted absolute and normalized RoM of lateral, anterior and posterior shear displacement showed comparable results as Janevic et al (1991). The predicted absolute values were within one SD of in vitro RoM, and the absolute differences of normalized ratios under $\mathrm{CFL}=2200 \mathrm{~N}$ were $1.4 \%$ for lateral shear, $6.2 \%$ for anterior shear, $0.7 \%$ for posterior shear.

For the full thoracolumbar spine (without rib cage), the normalized F/E RoM (under -8 to $6 \mathrm{Nm}$ ) to zero CFL (Fig. 7) were strongly correlated with experiment (Stanley et al., 2004) $(r=0.99$, $p<0.0001 ;$ slope $=1.03$, intercept $=-3.1^{\circ}$.

For the lumbar spine, the simulated decrease in lumbar F/E RoM with increasing CFL significantly correlated with experiment (Patwardhan et al., 2003) $(r=0.93, p=0.0171$; slope $=0.56$, intercept $=0.48^{\circ}$ ). Nevertheless, the experimentally observed decrease in RoM (Fig. 7) was slightly more significant compared to the finite element study (representing one subject) by (Shirazi-Adl, 2006). In vitro measurements of the CFL stiffening effect on lumbar LB and
AR were not found in the listed experiments in Table 1 . We compared AR predictions of lumbar FSUs (CFL $=1200 \mathrm{~N}$, external moment $=20 \mathrm{Nm}$ ) to (Shirazi-Adl, 2006) and found a close match: the normalized ratios of FSU RoM were $50 \%$ to $62 \%$ versus $60 \%$ to $65 \%$ for the simulations versus the finite element study.

For the thoracic spine (with rib cage), the simulated decrease in thoracic $\mathrm{F} / \mathrm{E}$ and AR RoM $( \pm 5 \mathrm{Nm})$ under $\mathrm{CFL}=400 \mathrm{~N}$ was also in agreement with experiments (Liebsch et al., 2018; Sis et al., 2016). The model slightly underestimated the experimentally observed decrease in thoracic LB: the decrease was $23.4 \%$ versus $38.9 \%$ in $\mathrm{F} / \mathrm{E}, 31.2 \%$ versus $33.2 \%$ in $\mathrm{AR}$, and $41.5 \%$ versus $76.8 \%$ in LB for the simulations versus experiment (Liebsch et al., 2018), and $23.8 \%$ versus $17.0 \%$ in $\mathrm{F} / \mathrm{E}, 33.6 \%$ versus $33.2 \%$ in $\mathrm{AR}$, and 48.4\% versus $72.1 \%$ in LB for the simulations versus experiment (Sis et al., 2016).

\section{Discussion}

We implemented a level-specific, nonlinear stiffness in a full thoracolumbar spine rigid-body model. Also stiffening effects of compressive load and thoracic spine interaction were successfully integrated.

In terms of the level-specific nonlinear stiffness behavior, the simulated multi- and mono-segmental RoM in the lumbar, thoracic and thoracolumbar spine were in good agreement with literature (averaged difference below $1.6^{\circ}$ ), despite the varying experimental setups, specimen characteristics and loading conditions across the 

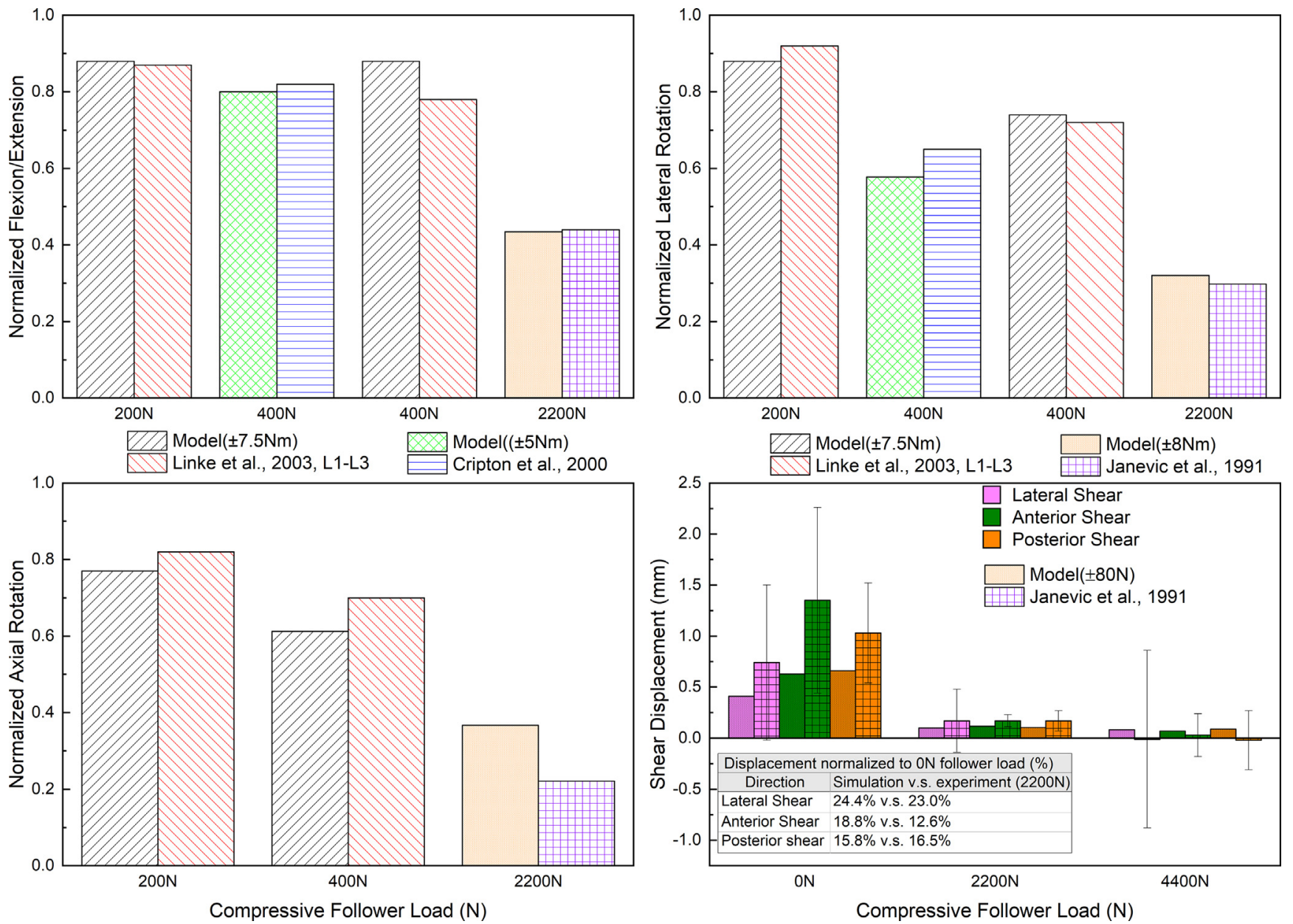

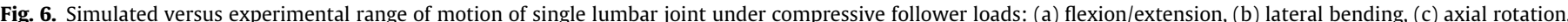

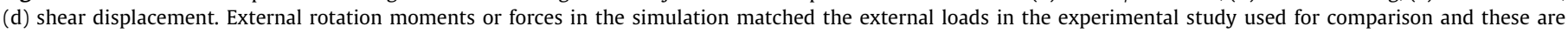

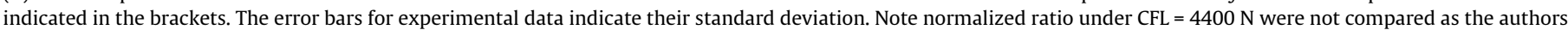

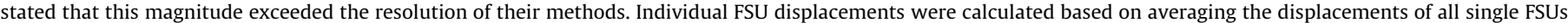
documented in the corresponding experiments.

available studies. Wheeler et al. (2011) quantified the maximum RoM differences of single FSU between various laboratoryspecific apparatuses always exceeded $1^{\circ}$. Thereby the observed level difference is in the order of measurement accuracy. Furthermore, the nonlinear stiffness formulation outperformed the linear stiffness expressions (Ignasiak et al., 2016; Senteler et al., 2016) in predicting the spinal kinematics.

Only a few biomechanical rigid-body models integrated the theoretical stiffness properties, let alone the stiffening effect through interaction with the rib cage (Ghezelbash et al., 2016; Ignasiak et al., 2016). Both were introduced in our study and resulted in accurate simulations comparable to experimental spinal kinematics measured in the presence (Liebsch et al., 2018; Sis et al., 2016) and absence (Stanley et al., 2004) of the rib cage. It should be noted that the rib cage effects were implicitly incorporated by stiffening FSUs, representing a simplification of the effects of the complex rib cage structure. If the rib cage and rib-vertebrae articulations are explicitly modelled, the stiffness formulation without the rib cage stiffening effect can be used. However, further validation might be necessary to evaluate the combined simulation effect.

In terms of stiffening effects from mulit-segment interactions, our stiffness formulation qualitatively captured the decrease of thoracic RoM in all three dimensions in the multi-segmental situations when compared to mono-segmental FSU test. For the lum- bar spine, since the relative in vitro RoM relationship used for modelling the FSU stiffness were from the entire lumbar spine (Panjabi et al., 1994) instead of mono-segments (see supplementary material), therefore the multiple segment interactions were incorporated implicitly. Such stiffening behavior were thought to be caused by structures like supraspinous and longitudinal ligaments that span several spinal joints but are typically cut during the mono-segmental test (Wilke et al., 2017).

Strong coupling motions were found between LB and AR, even although no coupling items were explicitly modelled. The overall coupling trend were in good agreement within vitro experiment (Cholewicki et al., 1996; Liebsch et al., 2018). This motion behavior is mainly due to the specific spine curvature (lordosis or kyphosis) (Cholewicki et al., 1996). Another contributing factor could be the adopted free joint definition with all rotational and translational DoF instead of a typically used 3DoF spherical joint. The resulting moving rotation center during the movement could also cause the secondary, coupled motions.

In terms of the stiffening effects of compressive load, we successfully simulated the CFL path in this rigid-body simulation, which approximates the spine curve, and minimize artefact moment and shear forces. Our model captured the decrease in spinal RoM under CFL as seen in in vitro experiments. The best matches were observed for the FE of the full thoracolumbar spine under CFLs up to $800 \mathrm{~N}$ (correlation factor $\mathrm{r}=0.99$; slope $=1.03$ ), 


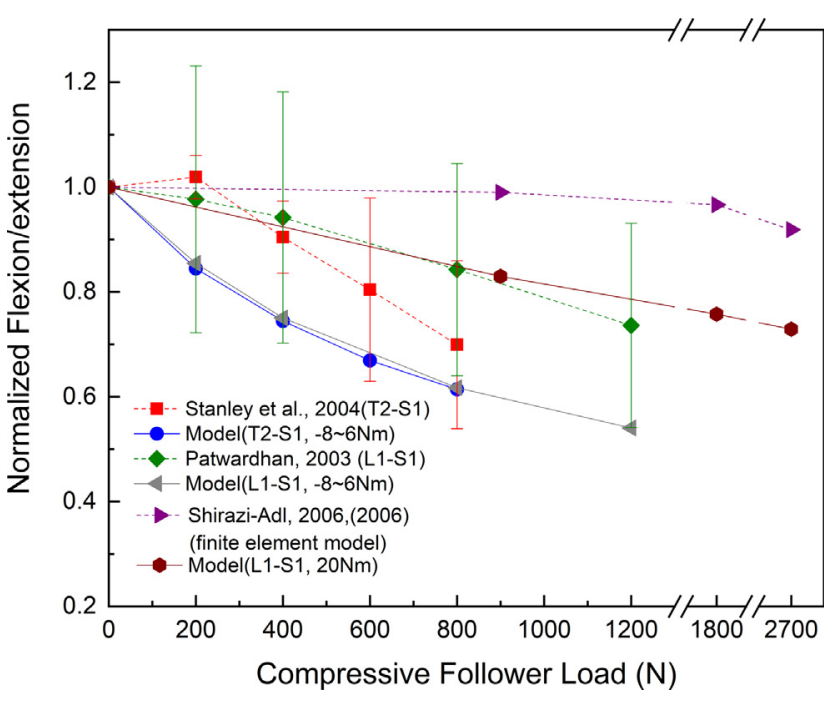

Fig. 7. Normalized range of flexion/extension of the thoracolumbar and lumbar spine to zero compressive follower load under different compressive follower loads. External flexion/extension moments in the simulation matched the external loads in the experimental study used for comparison and these are indicated in the brackets with corresponding spinal segments. The error bars for experimental data indicate their standard deviation.

and also for individual FSU rotations and translations under CFLs up to $2200 \mathrm{~N}$ (averaged differences around $0.7 \%$ to $9.4 \%$ ).

We observed slightly stiffer behavior in lumbar $\mathrm{F} / \mathrm{E}$ compared to (Patwardhan et al., 2003; Shirazi-Adl, 2006) and slightly less stiff response in thoracic LB under CFL compared to (Liebsch et al., 2018; Sis et al., 2016). This could be caused by specimen variance e.g., age and specimen physiological conditions. In addition, the slightly stiffer estimations of lumbar $\mathrm{F} / \mathrm{E}$ could be related to the experimental observation by (Linke et al., 2003; Patwardhan et al., 2003; Shirazi-Adl, 2006), who reported that the CFL stiffening effect was much more pronounced for smaller moments/rotations than larger ones. However, we did not account for the dependence of the CFL stiffening effect on FSU displacement because the experimental data (Stokes and Gardner-Morse, 2016) used to build the CFL stiffening effect was limited to only three CFL conditions $(C F L=0,250,500 \mathrm{~N})$ and typically smaller test RoM $\left( \pm 1^{\circ} \mathrm{F} / \mathrm{E}\right.$ and $\mathrm{AR}, \pm 1.5^{\circ} \mathrm{LB}$ ) than the physiological maximum RoM (Breen et al., 2019; Rozumalski et al., 2008). In addition, stiffening under CFL might be different in thoracic and lumbar spine FSUs due to differences in anatomy. Follow-up studies that test the compressive load effect on the physiological RoM of individual lumbar and thoracic FSUs are needed.

We presented a generic model of spine stiffness that does not account for geometrical factors like disc height and area or pathological conditions. Ghezelbash et al. (2016) scaled the passive properties in their finite element model by utilizing the conventional beam theory. Such scaling method is not applicable to the proposed lumped stiffness formulation. However, the formulation contains different parameter sets that account for differences in in vitro specimens, thereby capturing similar variance of in vitro load-displacement characteristics. Therefore, the model can be assumed to be less sensitive to inter-subject variance and thereby more representative for a wide range of individuals. In future work, combining the proposed generic stiffness formulation with stiffness calibration methods (e.g., optimization technique) will be developed to better describe subject-specific FSU mechanical behavior in pathological conditions.

In summary, we presented a novel model of non-linear FSU stiffness and integrated this model in an existing rigid-body model of the thoracolumbar spine. The stiffness formulations are compre- hensive enough to capture the physiological response of spinal kinematics under various loading conditions, and are also simple and generic enough to be used for various spine modelling studies. Our model will further our insight in spinal mechanics through more physiologically-accurate biomechanical simulations.

\section{Declaration of Competing Interest}

The authors have no conflicts of interest to declare.

\section{Acknowledgement}

The authors would like to acknowledge the financial support from China Scholarship Council (award to the first author, CSC NO. 201706230047) and the KU Leuven Internal Funds (Grant No. C24/17/095 - ASESP-P).

\section{Appendix A. Supplementary material}

Supplementary data to this article can be found online at https://doi.org/10.1016/j.jbiomech.2019.109437.

\section{References}

Abouhossein, A., Weisse, B., Ferguson, S.J., 2011. A multibody modelling approach to determine load sharing between passive elements of the lumbar spine. Comput. Methods Biomech. Biomed. Eng. 14, 527-537.

Azari, F., Arjmand, N., Shirazi-Adl, A., Rahimi-Moghaddam, T., 2018. A combined passive and active musculoskeletal model study to estimate L4-L5 load sharing. J. Biomech. 70, 157-165.

Breen, A., Hemming, R., Mellor, F., Breen, A., 2019. Intrasubject repeatability of in vivo intervertebral motion parameters using quantitative fluoroscopy. Eur. Spine J. 28, 450-460.

Bruno, A.G., Bouxsein, M.L., Anderson, D.E., 2015. Development and validation of a musculoskeletal model of the fully articulated thoracolumbar spine and rib cage. J. Biomech. Eng. 137, 081003.

Cazzola, D., Holsgrove, T.P., Preatoni, E., Gill, H.S., Trewartha, G., 2017. Cervical spine injuries: a whole-body musculoskeletal model for the analysis of spinal loading. PLoS One 12, e0169329.

Cholewicki, J., Crisco 3rd, J.J., Oxland, T.R., Yamamoto, I., Panjabi, M.M., 1996. Effects of posture and structure on three-dimensional coupled rotations in the lumbar spine. A biomechanical analysis. Spine (Phila Pa 1976) 21, 2421-2428.

Christophy, M., Curtin, M., Faruk Senan, N.A., Lotz, J.C., O'Reilly, O.M., 2012. On the modeling of the intervertebral joint in multibody models for the spine. Multibody Syst. Dyn. 30, 413-432.

Cripton, P.A., Bruehlmann, S.B., Orr, T.E., Oxland, T.R., Nolte, L.P., 2000. In vitro axial preload application during spine flexibility testing: towards reduced apparatusrelated artefacts. J. Biomech. 33, 1559-1568.

Dehghan-Hamani, I., Arjmand, N., Shirazi-Adl, A., 2019. Subject-specific loads on the lumbar spine in detailed finite element models scaled geometrically and kinematic-driven by radiography images. Int. J. Numer. Method Biomed. Eng. 35, e3182.

Delp, S.L., Anderson, F.C., Arnold, A.S., Loan, P., Habib, A., John, C.T., Guendelman, E., Thelen, D.G., 2007. OpenSim: open-source software to create and analyze dynamic simulations of movement. IEEE Trans. Biomed. Eng. 54, 1940-1950.

Dickey, J.P., Kerr, D.J., 2003. Effect of specimen length: are the mechanics of individual motion segments comparable in functional spinal units and multisegment specimens?. Med. Eng. Phys. 25, 221-227.

Ghezelbash, F., Eskandari, A.H., Shirazi-Adl, A., Arjmand, N., El-Ouaaid, Z., Plamondon, A., 2018. Effects of motion segment simulation and joint positioning on spinal loads in trunk musculoskeletal models. J. Biomech. 70, 149-156.

Ghezelbash, F., Shirazi-Adl, A., Arjmand, N., El-Ouaaid, Z., Plamondon, A., 2016. Subject-specific biomechanics of trunk: musculoskeletal scaling, internal loads and intradiscal pressure estimation. Biomech. Model Mechanobiol. 15, 16991712.

Guan, Y., Yoganandan, N., Moore, J., Pintar, F.A., Zhang, J., Maiman, D.J., Laud, P., 2007. Moment-rotation responses of the human lumbosacral spinal column. J. Biomech. 40, 1975-1980.

Han, K.S., Zander, T., Taylor, W.R., Rohlmann, A., 2012. An enhanced and validated generic thoraco-lumbar spine model for prediction of muscle forces. Med. Eng. Phys. 34, 709-716.

Heuer, F., Schmidt, H., Klezl, Z., Claes, L., Wilke, H.J., 2007. Stepwise reduction of functional spinal structures increase range of motion and change lordosis angle. J. Biomech. 40, 271-280.

Ignasiak, D., Dendorfer, S., Ferguson, S.J., 2016. Thoracolumbar spine model with articulated ribcage for the prediction of dynamic spinal loading. J. Biomech. 49, 959-966. 
ARTICLE IN PRESS

10

W. Wang et al./Journal of Biomechanics $x x x(x x x x) x x x$

Izzo, R., Guarnieri, G., Guglielmi, G., Muto, M., 2013. Biomechanics of the spine. Part I: spinal stability. Eur. J. Radiol. 82, 118-126.

Janevic, J., Ashton-Miller, J.A., Schultz, A.B., 1991. Large compressive preloads decrease lumbar motion segment flexibility. J Orthop. Res. 9, 228-236.

Kettler, A., Wilke, H.J., Haid, C., Claes, L., 2000. Effects of specimen length on the monosegmental motion behavior of the lumbar spine. Spine (Phila Pa 1976) 25 , 543-550.

Khoddam-Khorasani, P., Arjmand, N., Shirazi-Adl, A., 2018. Trunk hybrid passiveactive musculoskeletal modeling to determine the detailed T12-S1 response under in vivo loads. Ann. Biomed. Eng. 46, 1830-1843.

Liebsch, C., Graf, N., Appelt, K., Wilke, H.J., 2017. The rib cage stabilizes the human thoracic spine: an in vitro study using stepwise reduction of rib cage structures. PLoS One 12, e0178733.

Liebsch, C., Graf, N., Wilke, H.J., 2018. The effect of follower load on the intersegmental coupled motion characteristics of the human thoracic spine: An in vitro study using entire rib cage specimens. J. Biomech. 78, 36-44.

Linke, B., Meyer, G., Knoller, S., Schneider, E., 2003. Influence of preload in flexibility testing of native and instrumented lumbar spine specimens. Am. Soc. Test Mater. 1431, 173-190.

Liu, T., Khalaf, K., Adeeb, S., El-Rich, M., 2019. Effects of lumbo-pelvic rhythm on trunk muscle forces and disc loads during forward flexion: a combined musculoskeletal and finite element simulation study. J. Biomech. 82, 116-123.

Liu, T., Khalaf, K., Naserkhaki, S., El-Rich, M., 2018. Load-sharing in the lumbosacral spine in neutral standing \& flexed postures - a combined finite element and inverse static study. J. Biomech. 70, 43-50.

Malakoutian, M., Street, J., Wilke, H.-J., Stavness, I., Fels, S., Oxland, T., 2016. A musculoskeletal model of the lumbar spine using ArtiSynth - development and validation. Comput. Methods Biomech. Biomed. Eng.: Imag. Visualizat. 6, 483490.

Mannen, E.M., Friis, E.A., Sis, H.L., Wong, B.M., Cadel, E.S., Anderson, D.E., 2018. The rib cage stiffens the thoracic spine in a cadaveric model with body weight load under dynamic moments. J. Mech. Behav. Biomed. Mater. 84, 258-264.

Meng, X., Bruno, A.G., Cheng, B., Wang, W., Bouxsein, M.L., Anderson, D.E., 2015. Incorporating six degree-of-freedom intervertebral joint stiffness in a lumbar spine musculoskeletal model-method and performance in flexed postures. J. Biomech. Eng. 137, 101008.

Panjabi, M.M., Oxland, T.R., Yamamoto, I., Crisco, J.J., 1994. Mechanical behavior of the human lumbar and lumbosacral spine as shown by three-dimensional loaddisplacement curves. J. Bone Joint Surg. 76, 413-424.
Patwardhan, A.G., Havey, R.M., Carandang, G., Simonds, J., Voronov, L.I., Ghanayem, A.J., Meade, K.P., Gavin, T.M., Paxinos, O., 2003. Effect of compressive follower preload on the flexion-extension response of the human lumbar spine. J. Orthop. Res. 21, 540-546.

Renner, S.M., Natarajan, R.N., Patwardhan, A.G., Havey, R.M., Voronov, L.I., Guo, B.Y., Andersson, G.B., An, H.S., 2007. Novel model to analyze the effect of a large compressive follower pre-load on range of motions in a lumbar spine. J. Biomech. 40, 1326-1332.

Rozumalski, A., Schwartz, M.H., Wervey, R., Swanson, A., Dykes, D.C., Novacheck, T., 2008. The in vivo three-dimensional motion of the human lumbar spine during gait. Gait Posture 28, 378-384.

Senteler, M., Weisse, B., Rothenfluh, D.A., Snedeker, J.G., 2016. Intervertebral reaction force prediction using an enhanced assembly of OpenSim models. Comput. Methods Biomech. Biomed. Eng. 19, 538-548.

Shirazi-Adl, A., 2006. Analysis of large compression loads on lumbar spine in flexion and in torsion using a novel wrapping element. J. Biomech. 39, 267-275.

Sis, H.L., Mannen, E.M., Wong, B.M., Cadel, E.S., Bouxsein, M.L., Anderson, D.E., Friis, E.A., 2016. Effect of follower load on motion and stiffness of the human thoracic spine with intact rib cage. J. Biomech. 49, 3252-3259.

Stanley, S.K., Ghanayem, A.J., Voronov, L.I., Havey, R.M., Paxinos, O., Carandang, G., Zindrick, M.R., Patwardhan, A.G., 2004. Flexion-extension response of the thoracolumbar spine under compressive follower preload. Spine 29, E510E514.

Stokes, I.A.F., Gardner-Morse, M., 2003. Spinal stiffness increases with axial load: another stabilizing, consequence of muscle action. J. Electromyogr. Kinesiol. 13, 397-402.

Stokes, I.A.F., Gardner-Morse, M., 2016. A database of lumbar spinal mechanical behavior for validation of spinal analytical models. J. Biomech. 49, 780-785.

Weisse, B., Aiyangar, A.K., Affolter, C., Gander, R., Terrasi, G.P., Ploeg, H., 2012. Determination of the translational and rotational stiffnesses of an L4-L5 functional spinal unit using a specimen-specific finite element model. J. Mech. Behav. Biomed. Mater. 13, 45-61.

Wilke, H.J., Herkommer, A., Werner, K., Liebsch, C., 2017. In vitro analysis of the segmental flexibility of the thoracic spine. PLoS One 12, e0177823.

Yamamoto, I., Panjabi, M.M., Crisco, T., Oxland, T.O.M., 1989. Three-dimensional movements of the whole lumbar spine and lumbosacral joint. Spine 14, 12561260.

Please cite this article as: W. Wang, D. Wang, F. De Groote et al., Implementation of physiological functional spinal units in a rigid-body model of the tho-

racolumbar spine, Journal of Biomechanics, https://doi.org/10.1016/j.jbiomech.2019.109437 